\title{
Article
}

\section{Studies on Indigenous Ion Exchange Resins III: Column Characteristics}

\author{
Swaminathan Shankar ${ }^{1}$ and Balakrishnan Venkataramani ${ }^{2 *}$ \\ ${ }^{1}$ Hot Cell Development \& Engineering Section, ${ }^{2}$ Analytical Chemistry Division, \\ Bhabha Atomic Research Centre, Trombay, Mumbai 400 085, India
}

(Manuscript submitted May 5, 2007; accepted July 23, 2007)

\begin{abstract}
The column characteristics of gel-type, macroporous and nuclear grade strongly acidic cation exchange resins from three Indian manufacturers were studied for the exchange of $\mathrm{Na}^{+}, \mathrm{Cs}^{+}$, $\mathrm{Ca}^{2+}$ and $\mathrm{Sr}^{2+}$ with respect to hydrogen ion. The ion exchange isotherms and the equilibrium constants were evaluated from the breakthrough curves using the equation given by Glueckauf and were compared with that obtained by equilibrium batch experiments. In general, the equilibrium constants derived from column experiments were comparable to batch experiments in the case of $\mathrm{Na}$ and $\mathrm{Ca}$ ions and lower than that obtained from batch technique for $\mathrm{Cs}$ and $\mathrm{Sr}$ ions. Results also indicated that among the nine resins evaluated, no single resin showed good selectivity for both Cs and Sr ions; two different resins would have to be chosen for the removal of these elements present in the Low-level Liquid Waste (LLW) stream.
\end{abstract}

Key words: Indian resins, gel-type, macroporous, nuclear grade, column characteristics, alkali metal ions, alkaline earth metal ions, low level liquid waste

\section{Introduction}

Choice of ion exchange process as separation and purification technique is due to the ease with which it can be operated dynamically using a column. As compared to the batch experiments, the attainment of ion exchange equilibrium between the ions in the solution and the resin phase depends on the kinetics of exchange $[1,2]$. The shape of the breakthrough curve indicates whether the ion exchange equilibrium between the desired ion and the ion used as eluant is favorable or not. A sharp breakthrough is the one desired for column application. The equilibrium constant $(K)$ for the ion exchange process can also be obtained by analyzing the boundary in the breakthrough or elution curve $[1,3]$ and compared with those obtained by batch experiments. Very few attempts have been made in this regard [3].

Ion exchange equilibria involving alkali metal ions (Part I of the series, [4]) and alkaline earth metal ions (Part II of the series [5]) using the Indian resins have been studied by batch technique. In the present study, the efficacy of the resins to selectively sorb the ions of interest in low level radioactive waste stream, namely, $\mathrm{Cs}^{+}$and $\mathrm{Sr}^{2+}$, have been evaluated in a column and their relative performances assessed with respect to one more ion, namely $\mathrm{Na}^{+}$and $\mathrm{Ca}^{2+} ; \mathrm{Na}^{+}$is commonly present in all waste effluents, $\mathrm{Ca}^{2+}$ has been chosen because most of the resins, under present study, show a preference for $\mathrm{Ca}^{2+}$ over other alkaline earth metal ions [5]. The equilibrium constants evaluated from the analysis of the breakthrough curves have been compared with those obtained by batch techniques $[4,5]$.

Gel- and macroporous- type and nuclear grade strongly acidic cation exchange resins (designated as G, MP and $\mathrm{N}$ resins having the functional group $-\mathrm{SO}_{3}{ }^{-}$) obtained from three Indian manufacturers (designated 1,2 and 3 and the resins as G1, G2, G3; MP1, MP2, MP3 and N1, N2, N3) have been used in the present investigation. Their performance has been compared with data obtained (in this study) using imported resins, gel-type (Dowex $50 \mathrm{Wx} 4$ and Dowex 50Wx8) and macroporous resin (Amberlyst-15).

\section{Experimental}

Five gram of $\mathrm{H}^{+}$form of the air-dried resin was packed into a glass column fitted with a sintered glass disc, as slurry and allowed to settle as a closely packed bed. A known concentration of the chloride solution of the alkali metal and alkaline earth metal ions $\left(0.1 \mathrm{~mol} \mathrm{dm}^{-3} \mathrm{NaCl}, 0.05 \mathrm{~mol} \mathrm{dm}^{-3} \mathrm{CsCl}\right.$ and $0.025 \mathrm{~mol} \mathrm{dm}^{-3} \mathrm{Ca}$ and $\mathrm{Sr}$ chlorides $)$ was passed through the column at a slow flow rate ( 2 to $4 \mathrm{ml}$ per min.). $10 \mathrm{ml}$ aliquots of the effluent were collected and 
analysed for $\mathrm{H}^{+}$(in the case of alkaline metal ion) using standard $\mathrm{NaOH}$ and the alkaline earth metal ions by EDTA titration. In the case of alkali metal ions the column operations were terminated when the $\mathrm{H}^{+}$concentration was below detectable limits and those for alkaline earth metal ions when the effluent and influent concentrations became nearly equal.

The concentration of the metal ion $(\mathrm{meq} / \mathrm{ml}$ or $\mathrm{meq} / 10 \mathrm{ml})$ in the effluent was plotted against the volume of the effluent collected to obtain the breakthrough curves (Fig. 1). As the ions being analysed differ in the case of alkali metal and alkaline earth metal ions, the curves apparently looks like desorption (alkali metal ions) and sorption (alkaline earth metal ions).

\subsection{Analysis of the Breakthrough Curves (Fig. 1)}

\section{Treatment of the Experimental Data}

The boundary in the breakthrough or an elution curve of a column experiment represents the equilibrium of the solute between the exchanger and solution phases. It is possible to calculate the ion exchange isotherms and thereby the selectivity coefficients from these chromatographic experiments $[1,6]$ and the method can be used for mixed component system also. The functional relation between the concentration $C_{I}$ of the solute $I_{I}$ in the solution phase and the concentration $C_{i}$ of the same solute in the exchanger phase in equilirbium with $C_{i}$ is given by [1].

$$
C_{I}=\frac{Q_{I}(V)+\left(V-\beta V_{b}\right) C_{i}}{\left(1+\beta V_{b}\right)}
$$

where $Q_{I}(V)$ is the total amount of the $i$ remaining in the column after passing $V$ volume of solution., $V=$ volume at which the concentration of the effluent is $C_{I}$ (estimated experimentally), $V_{b}=$ total volume of the column (or bed volume), $\beta$ = functional void volume. Though the column was packed well, a fractional void volume of $10 \%$ was used in the calculation. $Q_{I}(V)$ is calculated by graphical integration. The application of Eqn. 1 to a set of different values of $C_{I}$ gives $C_{I}$, as a function of $C_{I}$, that is, the desired isotherm.

In the derivation of Eqn. 1, local equilibrium in the layers of the column is assumed. Although under normal condition, ion exchange columns do not operate in local equilibrium, the technique of determining the isotherm from column experiments can be used to compare the performance of a set of resins functioning under same set of column conditions.

\subsection{Evaluating the Equilibrium constants}

The above analysis of the breakthrough curve gives the values of $C_{I}$ (meq. in the solution) and $C_{i}$ (meq) present in total amount of the resin bed, at equilibrium. From these the equivalent fraction of the ions in solution $\left(N_{M}\right)$ and resin phase $\left(\bar{N}_{M}\right)$ can be calculated, knowing the concentration of the influent solution and the capacity of the $\mathrm{H}^{+}$ form of the resin used in the column (capacity $\mathrm{X}$ amount used.) These values were used to plot the ion exchange isotherms ( $\bar{N}_{M}$ vs $N_{M}$ plots) (Fig. 2). Evaluation of equilibrium constants from the ion exchange isotherms has been discussed in detail earlier [6,7]. Hence, only the final equations are given and discussed.

Equilibrium constants for the alkali metal ion $-\mathrm{H}^{+}$exchange, is given by [4]

$$
\begin{aligned}
& \mathrm{R}-\mathrm{H}+\mathrm{M}^{+} \Leftrightarrow \mathrm{R}-\mathrm{M}+\mathrm{H}^{+} \\
& \log K=\int_{0}^{1} \log K_{c} d \overline{N_{M}}+2 \log \frac{\gamma_{ \pm H C l}}{\gamma_{ \pm M C l}}
\end{aligned}
$$

Equilibrium constants for the alkaline earth metal ion $-\mathrm{H}^{+}$exchange, is given by [5]

$$
2 \mathrm{R}-\mathrm{H}+\mathrm{M}^{2+} \Leftrightarrow(\mathrm{R})_{2}-\mathrm{M}+2 \mathrm{H}^{+}
$$

$$
\log K=-1+{ }^{1} \int_{0} \log K_{c} \mathrm{~d} \bar{N}_{M}
$$

In the case of uni- uni-valent exchange system, $K_{c}$ is the stoichiometric concentration product [4] and for the uni- bivalent exchange systems, $K_{c}$ is the stoichiometric concentration product multiplied by the activity coefficient ratio [5]. The mean activity coefficient of the electrolyte in solution phase can be obtained from the literature [7].

The $\log K_{c}$ vs $\bar{N}_{M}$ plots for the alkali metal and alkaline earth metal ions $-\mathrm{H}^{+}$exchange systems are given in Fig. 3. For the sake of comparison, the $\bar{N}_{M}$ vs $N_{M}$ and $\log K_{c}$ vs $\bar{N}_{M}$ plots obtained in the case of respective batch experiments are also included in these figures. 
Tables 1 and 2 give the capacities realised during the column experiments (compared with the expected values, based on the amount of resin used). The Tables also give the equilibrium constant obtained from column experiments and those obtained by batch techniques [4,5].

\section{Results and Discussion}

The ion exchange resins from the Indian manufacturers have been prepared by polymerising styrene with divinyl benzene as cross linking agent. The polymer is later sulphonated. The extent of cross-linking varies from different manufacturer; it will be in the range of 6 to $8 \%$. The nuclear grade resins have higher attrition resistance than gel-type resins. Macroporous resins are prepared using an inert compound during polymerization which is removed later. These resins are mainly used in demineralization plants to prepare high purity water. As 12 types of resins have been used in the present study, only typical curves representing their performance are included in the paper.

In the present study, only a practical approach to evaluate the column characteristics has been attempted, essentially to screen the different resins available in the Indian market. The resins are evaluated based on the capacity realisable, shape of the breakthrough curves and comparison between the ion exchange isotherms and equilibrium constants obtained from batch (equilibrium) technique and column operation.
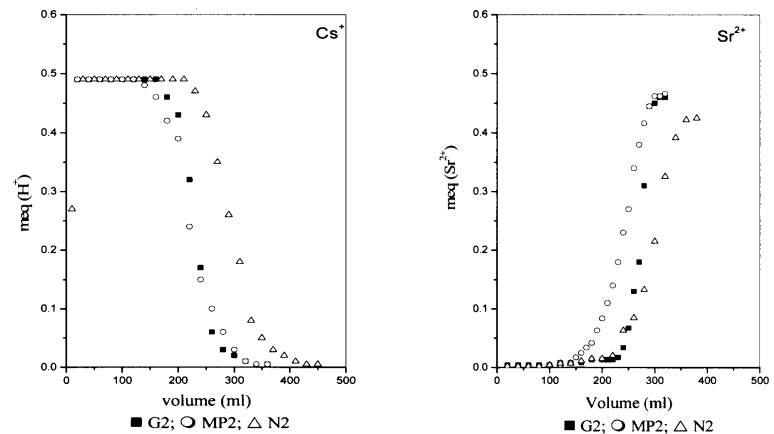

Fig. 1 Breakthrough curves for $\mathrm{Cs}^{+}$ions and $\mathrm{Sr}^{2+}$ on indigenous resins
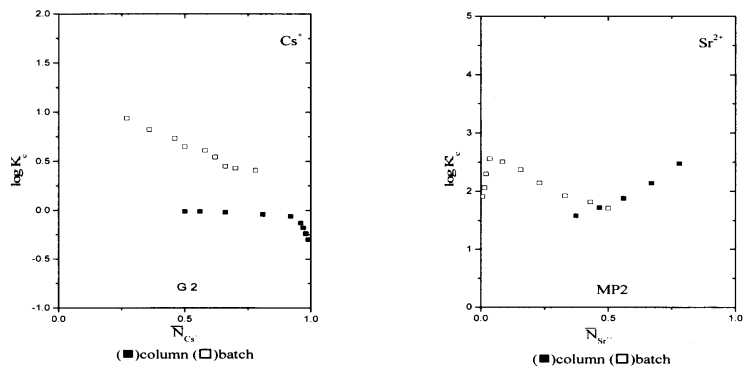

Fig. $3 \log K_{c}$ vs $\bar{N}_{M}$ plots for indigenous resins

Selectivity $\left(\bar{N}_{M}\right)$ for $\mathrm{Na}^{+}$is nearly the same as for batch experiments. On the other hand, the selectivity for $\mathrm{Cs}^{+}$is, in general, lower during column operation than in the batch process. The selectivity for $\mathrm{Ca}^{2}$ and $\mathrm{Sr}^{2+} \mathrm{during}^{2}$ column operation is lesser than in batch experiments. Among the resins, MP2 shows reasonably similar behaviour in both techniques for $\mathrm{Ca}^{2+}$ and $\mathrm{Sr}^{2+}$ and $\mathrm{G} 1$ for $\mathrm{Sr}^{2+}$.

The analysis of the $\log K_{c}$, vs $\bar{N}_{M}$ plots shows similar and matching trends for both the techniques for $\mathrm{Na}^{+}$and no similarity between the two techniques in the case of $\mathrm{Cs}^{+}$. Similar trends for $\mathrm{Ca}^{2+}$ and $\mathrm{Sr}^{2+}$ in both batch and column techniques are shown by some of the resins.

The equilibrium constants evaluated from the $\log K_{c}$ vs $\bar{N}_{M}$ plots, after incorporating necessary corrections for solution phase activity coefficients show higher selectivity for $\mathrm{Na}^{+}$for all the resins in column operation than the batch experiments; selectivity for $\mathrm{Cs}^{+}$during column operation is extremely poor for all the resins. The equilibrium constants for $\mathrm{Ca}^{2+}$ are higher for some of the resins and much lower selectivity for $\mathrm{Sr}^{2+}$ under column conditions than the batch technique. 
Based on the mixed trends shown by the Indian resins under dynamic column conditions, it can be concluded that the resins are generally tailor-made for general industrial water treatment purposes (removal of hardness cation and other ions) and are not specific for applications like removal of $\mathrm{Cs}^{+}$and $\mathrm{Sr}^{2+}$ present in nuclear waste streams As far as $\mathrm{Cs}^{+}$is concerned, the resins tested are not showing encouraging results.

From the point of view of shape of the breakthrough curve, the isotherms and selectivity, overall performance of the resin MP2 for $\mathrm{Sr}^{2+}$ is better than other resins. G2 has a higher selectivity under dynamic condition for Cs ${ }^{+}$.

Table: 1 Column characteristics on Alkali Metal ions - $\mathrm{H}^{+}$exchanges on indigenous ion exchange resins

\begin{tabular}{|c|c|c|c|c|c|c|c|c|c|c|}
\hline Resin & $\begin{array}{c}\text { Exchange } \\
\text { System }\end{array}$ & $\begin{array}{c}\mathrm{BV} \\
(\mathrm{ml})\end{array}$ & $\log \mathrm{K}$ & $\mathrm{K}$ & $\mathrm{K}^{*}$ & $\begin{array}{c}\text { Exchange } \\
\text { System }\end{array}$ & $\begin{array}{c}\mathrm{BV} \\
(\mathrm{ml})\end{array}$ & $\log \mathrm{K}$ & $\mathrm{K}$ & $\mathrm{K}^{*}$ \\
\hline $\mathrm{G} \mathrm{1}$ & $\mathrm{Na}^{+}-\mathrm{H}^{+}$ & 7.9 & 0.52 & 3.31 & 1.64 & $\mathrm{Cs}^{+}-\mathrm{H}^{+}$ & 7.9 & 0.143 & 0.72 & 3.30 \\
\hline G 2 & & 7.2 & 0.75 & 5.62 & 1.24 & & 7.1 & 0.017 & 1.04 & 3.38 \\
\hline G 3 & & 7.9 & 0.10 & 1.26 & 1.25 & & 8.2 & 0.513 & 0.31 & 2.73 \\
\hline MP 1 & & 7.6 & 0.18 & 1.51 & 1.69 & & 7.7 & 0.583 & 0.26 & 2.72 \\
\hline MP 2 & & 7.6 & 0.50 & 3.16 & 1.31 & & 8.1 & 0.253 & 0.56 & 4.84 \\
\hline MP 3 & & 8.1 & 0.75 & 5.62 & 0.26 & & 7.5 & 0.073 & 0.85 & 1.65 \\
\hline N 1 & & 7.2 & 0.62 & 4.17 & 1.13 & & 8.0 & 0.273 & 0.53 & 2.84 \\
\hline N 2 & & 8.0 & 0.58 & 3.80 & 1.62 & & 8.0 & 0.263 & 0.55 & 2.83 \\
\hline N 3 & & 7.9 & 0.20 & 1.58 & 0.66 & & 8.0 & 0.343 & 0.45 & 1.55 \\
\hline Dowex 50Wx4 & & 8.0 & 0.48 & 3.02 & 1.85 & & 8.2 & 0.223 & 0.60 & 1.60 \\
\hline Dowex 50Wx8 & & 6.3 & 0.55 & 3.55 & 1.42 & & 7.3 & 0.143 & 0.72 & 3.37 \\
\hline Amberlyst-15 & & 7.7 & 0.43 & 2.69 & 1.73 & & 7.3 & 0.193 & 0.64 & 3.97 \\
\hline
\end{tabular}

$\mathrm{BV}=$ Bed Volume

* Equilibrium constant (K) by batch method (from Ref. 4)

Table 2 Column characteristics on Alkaline Earth Metal ions $-\mathrm{H}^{+}$exchanges on indigenous ion exchange resins

\begin{tabular}{|c|c|c|c|c|c|c|c|c|c|c|}
\hline Resin & $\begin{array}{c}\text { Exchange } \\
\text { System }\end{array}$ & $\begin{array}{c}\mathrm{BV} \\
(\mathrm{ml})\end{array}$ & $\begin{array}{c}\text { log } \\
\mathrm{K}\end{array}$ & $\mathrm{K}$ & $\mathrm{K}^{*}$ & $\begin{array}{c}\text { Exchange } \\
\text { System }\end{array}$ & $\begin{array}{c}\mathrm{BV} \\
(\mathrm{ml})\end{array}$ & $\log \mathrm{K}$ & $\mathrm{K}$ & $\mathrm{K}^{*}$ \\
\hline G 1 & $\mathrm{Ca}^{++}-\mathrm{H}^{+}$ & 7.1 & 1.501 & 31.70 & 9.33 & $\mathrm{Sr}^{++}-\mathrm{H}^{+}$ & 7.1 & 0.605 & 4.02 & 4.61 \\
\hline G 2 & & 8.1 & 1.512 & 32.51 & 9.27 & & 8.3 & 0.585 & 3.84 & 7.28 \\
\hline G 3 & & 9.0 & 0.185 & 1.53 & 19.95 & & 8.5 & 1.325 & 21.15 & 25.12 \\
\hline MP 1 & & 7.7 & 0.832 & 6.80 & 24.55 & & 8.0 & 1.045 & 11.10 & 9.77 \\
\hline MP 2 & & 8.9 & 1.973 & 93.97 & 18.53 & & 7.3 & 1.176 & 14.99 & 7.92 \\
\hline MP 3 & & 7.2 & 0.516 & 3.28 & 16.60 & & 8.0 & 0.265 & 1.84 & 22.39 \\
\hline N 1 & & 8.8 & 1.645 & 44.16 & 10.57 & & 7.9 & 0.634 & 4.31 & 8.51 \\
\hline N 2 & & 8.8 & 0.305 & 2.02 & 11.64 & & 8.0 & 0.754 & 5.68 & 7.87 \\
\hline N 3 & & 9.0 & 2.012 & 102.90 & 7.10 & & 7.3 & 0.915 & 8.23 & 18.24 \\
\hline Dowex 50Wx4 & & 8.5 & 2.116 & 130.74 & 10.14 & & 8.1 & 1.384 & 24.18 & 5.90 \\
\hline Dowex 50Wx8 & & 8.9 & 2.489 & 308.32 & 20.70 & & 8.1 & 0.833 & 6.80 & 6.26 \\
\hline Amberlyst-15 & & 7.5 & 0.380 & 2.40 & 22.20 & & 7.3 & 0.262 & 1.83 & 2.03 \\
\hline
\end{tabular}

$\mathrm{BV}=\mathrm{Bed}$ Volume $\quad *$ Equilibrium constant $(\mathrm{K})$ by batch method (from Ref.5)

\section{References}

1. F. Helfferich, Ion exchange, McGraw Hill and Co., New York, 1962.

2. C.E. Hartand, Ion exchange: Theory and practice ( $2^{\text {nd }}$ Edn.), Royal Soc. Chem., Cambridge, 1994.

3. K.L.N. Rao, K.S. Sarma, C. Mathew, A.K. Jadhav, J.P. Shukla, N. Natarajan, T.K. Seshadri, S.K. Sali, V.I. Dhiwar, B.M. Pande and B. Venkataramani, J. Chem. Soc. Faraday Trans. 94, 1641-1647 (1998).

4. S.Shankar and B.Venkatarmani, Part I of the series in ICIE'07 (this Journal)

5. Shankar and B.Venkatarmani, Part II of the series in ICIE'07(this Jurnal)

6. E. Glueckauf, Nature (London), 156, 748-749 (1945); J. Chem. Soc., 3280-3285 (1949).

7. R.A.Robinson and R.H.Stokes, Electrolytic solutions, Butterworth, London, 1969. 